\title{
Formulation, Optimization and Evaluation of Non-aerosol Topical Spray of Lidocaine for Pain Management
}

\author{
Neelam Pawar ${ }^{1}$, Anoop Parmar ${ }^{1}$, Kavita Bahmanii ${ }^{1,}$, DN Mishra ${ }^{1}$, Renu Malik², Neha Minocha ${ }^{3}$, Pawan Jalwal ${ }^{2}$, Rahul Pawar $^{4}$ \\ 'Department of Pharmaceutical Sciences, Chaudhary Bansi Lal University, Bhiwani, Haryana, INDIA. \\ 2Department of Pharmaceutical Sciences, Baba Masthnath University, Rohtak, Haryana, INDIA. \\ ${ }^{3}$ School of Medical and Allied Sciences, KR Manglam University, Gurugram, Haryana, INDIA. \\ ${ }^{4}$ Department of Pharmaceutical Sciences, Guru Jambheshwar University Science and Technology, Hisar, Haryana, INDIA.
}

\begin{abstract}
Background: The optimization study was conducted in an attempt to develop a non-pressurized topical spray of Lidocaine without propellant. Methods: Central composite design was selected to determine the best conditions for the formulation of sprays with two independent factors were prepared $(\mathrm{pH}$ adjuster i.e sodium citrate and penetration enhancer i.e. propylene glycol). Concentration of propylene glycol (X1) of $(5-25 \mathrm{ml})$ and sodium citrate $(\mathrm{X} 2)$ of $(0.5-2.0 \mathrm{ml})$ was the value range of the variables. F5 was ideally suited for use by spraying the container of a pump spray. Results: The drug content of F5 was $98.8 \%$ which indicates that the drug is distributed almost uniformly throughout the formulation and that there was no loss of drug in the formulation. Evaporation time and total number of delivery of F5 batch was about 2 min and 487. Drug content per actuation, diffusion study of F5 and marketed formulation were 97.64, 98.88 (at 6hr) and 68.64 (at $6 \mathrm{hr}$ ) respectively. The best fitted model for the drug content and evaporation time was quadric fit provided the value of $r^{2}(0.9070$ and
\end{abstract}

0.974) respectively. Conclusion: The research work concludes about the successful preparation of non-pressurized Lidocaine spray with local anesthetic action.

Key words: Non-pressurized Topical Spray, Lidocaine, Meter Dose, Actuator, High-Density Polyethylene Plastic Bottles.

\section{Correspondence}

Ms. Neelam Pawar,

Department of Pharmaceutical Science, Chaudhary Bansi Lal University, Bhiwani-127021, INDIA.

Email id: neelampawar5555@gmail.com;

ORCID: 0000-0003-2553-8950

DOI: $10.5530 /$ ijpi.2021.4.74

\section{INTRODUCTION}

Lidocaine is an anesthetic of the amide type. Establish the neuronal membrane by inhibiting the ionic flux necessary for the initialization and transmission of the impulse, acting as a local anesthetic accessory. ${ }^{1}$ This leads to reverse the sodium channels from the inside that avoids depolarization of the nerve. Indeed, with sufficient interruption, the membrane of the postsynaptic neuron was not depolarized in the end; at least, it is not possible to express an action potential. There is not transmittance of signals to the brain, while this is the cause of the prevention pain signal from the primary source and produces an anesthetic effect. Lidocaine is used extensively in anesthesia, pain, irritation, hemorrhoids, posterior neuralgia, and examination of gastrointestinal tract infection. ${ }^{2}$

Spray may be in the form of coarse droplets or finally divided solids of aqueous or oleaginous solution which means to be applied to topically and nasal pharyngeal tract. These suspensions and solution were then filled into the spraying bottles. The pharmaceutical solution comprises a therapeutic agents and different types of excipients dissolved in suitable solvents. The solution delivered the drug to the target site by placing the spray container gently on the skin and releasing the spray by triggering it. The drug spreads onto the skin surface and then absorbed. ${ }^{3}$ The composition of topical spray as per the literature comprises of medicament, film, farmer, vehicles, penetration enhancers, solublizer, plasticizer and watersoluble additives. ${ }^{4}$

Topical Drug Delivery System can be classified into two drug delivery systems i.e. Pressurized topical Spray (Aerosol) and Non-pressurized topical spray. Pressurized topical sprays are in the form of liquid goutlets, solid particles or carrier gas that compress or liquidate under container pressure. It is delivered as a fine solid particle, a liquid mist, at the point of application when the pressure drops into the container. ${ }^{5}$ Non-pressurized topical spray does not hold any kind of propellant, these formulations are additional user friendly, engrave cost of formulation as propellants are pricey, environmentally tolerable, simple to apply and supplementary further patient conventionality. The method of dispensing formulation is spray pump function on mechanical energy which is offered by the triggering actuator. ${ }^{6}$

The objective of the study is work was to develop a non-pressurized spray formulation for transdermal delivery of Lidocaine and to carry out the in vitro characterization of the optimized formulation. Lidocaine release from Propylene Glycol, Citric acid and Peppermint oil based formulation was assessed in vitro and developed formulation was used for delivery from a metered dose spray. Various qualitative and quantitative parameters like $\mathrm{pH}$, evaporation time, and average weight, uniformity of weight and in vitro permeation were evaluated.

\section{MATERIALS AND METHODS}

\section{Material}

Lidocaine was gifted by Belco Pharmaceutical Ltd., Bahadurgarh. The excipients like sodium citrate, oil of peppermint were purchased from Himedia, propylene glycol were obtained from Sisco Research laboratories Pvt. Ltd. Mumbai, India. Inactive Ingredient Limits According to Food Drug and Administration (FDA) were Propylene Glycol (50.30\%), Citric acid (40\%), Peppermint oil (0.20\%). 
Various ingredients as mentioned in the literature for topical sprays were studied in the Handbook of Pharmaceutical Excipient for their functional category, applications in pharmaceutical formulations, physical properties, solubility, and incompatibility. A solvent system was selected based on the drug solubility and penetration enhancer, cooling agent, plasticizers, and film-forming agents were chosen based on their solubility in a solvent system, compatibility with the drug and their topical application. The limits of excipients for topical applications were studied in the literature. ${ }^{7}$ Propylene glycol was extensively used as a solvent, disinfectant, antimicrobial, preservative, plasticizer, humectants, stabilizing agent, and water-miscible co-solvent. Sodium citrate was used in pharmaceutical products to modify the $\mathrm{pH}$ of solutions, sequestering agent, and blood anticoagulants. Peppermint Oil was chosen for cooling effect to give a good and pleasant odor along with mint flavor in the formulation. Menthol was the basic component in peppermint oil which provides cooling sensation after topical application. Limits of excipient in topical preparations as per FDA are given below in Table $1 .{ }^{8}$

\section{Methods}

Non- Pressurized topical spray system was selected to avoid the use of inflammable propellant. The spray systems were available in two forms:

- $\quad$ Pressurized Topical Spray System

- $\quad$ Non-pressurized Topical Spray System

Without the presence of any harmful propellant non-pressurized topical sprays may reduce various side effects of the formulation on skin. A development of non-pressurized spray of lidocaine provides the maximum amount of drug on site and was easy to apply. ${ }^{8-10}$

\section{Selection of Packaging Component}

Meter dose non-pressurized topical spray of lidocaine has three main components. Spray Pumps, actuator and bottles were done based on the container used in the marketed formulation of other spray products. Actuator (RS3.L.TM) was selected depending upon the type of container used. Metering values $200 \mathrm{mcl}$ pumps (Aptar) were taken to deliver propellant free delivery as the external pressure used in actuator. There are 2 types of pumps in this market depending upon the valve, i.e., metered valve or continuous valve. Wide ranges of pumps with dose volume from $50 \mu \mathrm{l}$ to $220 \mu \mathrm{l}$ were available, with various actuators, with no elastomeric gasket. For dermal spray and dispensing system, 161 and 137 DD (Drug Delivery) with dose volume 50 $\mu \mathrm{l}, 70 \mu \mathrm{l}, 90 \mu \mathrm{l}, 100 \mu \mathrm{l}$, $130 \mu \mathrm{l}, 140 \mu \mathrm{l}, 170 \mu \mathrm{l}, 200 \mu \mathrm{l}$, and $220 \mu \mathrm{l}$ in form of Screw-On, Snap-On, and Crimp-On was available. 150ml Screw Neck HDPE (High-Density Polyethylene) bottles were designated based on the containers used in the marketed formulation of other non-pressurized spray products. HDPE spray bottle for cosmetic/ pharmaceutical/ medical products with over cap derives numerous volumes, $30 \mathrm{ml}, 40 \mathrm{ml}, 50 \mathrm{ml}, 70 \mathrm{ml}, 80 \mathrm{ml}$, $100 \mathrm{ml}$, and $150 \mathrm{ml}$ which were conformed to the national standard in pharmaceutical/ food hygiene and safe to use. These bottles were likewise of three types Screw-On, Crimp-On, and Snap-On. Specially designed plastic bottles with screw-type were utilized for filling the topical spray formulations. Screw Neck HDPE bottle were suitable for atomizers and pumps. $^{8-11}$

Table 1: Design Expert of Lidocaine without Propellant Topical Spray with Independent and Dependent Variables and Model summary statistics analysis for response.

\begin{tabular}{|c|c|c|c|c|c|}
\hline \multirow{2}{*}{$\begin{array}{l}\text { Batch } \\
\text { Run }\end{array}$} & Factor $1(\mathrm{X} 1)$ & \multicolumn{2}{|c|}{ Factor 2(X2) } & Response (Y1) & Response (Y2) \\
\hline & $\begin{array}{l}\text { A:Propylene Glycol } \\
\text { (ml) }\end{array}$ & \multicolumn{2}{|c|}{$\begin{array}{l}\text { B:Sodium Citrate } \\
\text { (mg) }\end{array}$} & $\begin{array}{c}\text { Evaporation Time } \\
\text { (min) }\end{array}$ & $\begin{array}{l}\text { Drug Content } \\
\text { (mg) }\end{array}$ \\
\hline 1 & 5 & \multicolumn{2}{|c|}{0.5} & 2.89 & 95.96 \\
\hline 2 & 15 & \multicolumn{2}{|c|}{1.25} & 2.77 & 98.31 \\
\hline 3 & 15 & \multicolumn{2}{|c|}{1.25} & 2.56 & 98.56 \\
\hline 4 & 15 & \multicolumn{2}{|c|}{0.18934} & 2.32 & 93.21 \\
\hline 5 & 25 & \multicolumn{2}{|c|}{2} & 3.87 & 93.27 \\
\hline 6 & 0.857864 & \multicolumn{2}{|c|}{1.25} & 2.45 & 94.83 \\
\hline 7 & 5 & \multicolumn{2}{|c|}{2} & 2.91 & 91.31 \\
\hline 8 & 15 & \multicolumn{2}{|c|}{1.25} & 2.75 & 98.55 \\
\hline 9 & 15 & \multicolumn{2}{|c|}{1.25} & 2.81 & 98.67 \\
\hline 10 & 15 & \multicolumn{2}{|c|}{1.25} & 2.43 & 98.55 \\
\hline 11 & 29.1421 & \multicolumn{2}{|c|}{1.25} & 4.87 & 94.67 \\
\hline 12 & 25 & \multicolumn{2}{|c|}{0.5} & 4.04 & 96.99 \\
\hline 13 & 15 & \multicolumn{2}{|c|}{2.31066} & 3.22 & 95.55 \\
\hline \multirow{2}{*}{$\begin{array}{c}\text { Model } \\
R^{2}\end{array}$} & \multicolumn{3}{|c|}{ Y1(Evaporation Time) } & \multicolumn{2}{|c|}{ Y2( Drug Content) } \\
\hline & Adjusted $R^{2}$ & Predicted $R^{2}$ & $R^{2}$ & Adjusted $R^{2}$ & Predicted $R^{2}$ \\
\hline Linear & 0.5800 & 0.4960 & 0.0574 & 0.1313 & 0.6453 \\
\hline $2 \mathrm{~F} 1$ & 0.5813 & 0.4417 & 0.0604 & 0.2528 & 1.5643 \\
\hline Quadratic & 0.9070 & 0.8405 & 0.7441 & 0.5614 & 0.8115 \\
\hline
\end{tabular}




\section{Formulation Development}

All ingredients were weighed accurately. All containers were cleaned, washed properly with ethanol, and dried in air. The drugs were dissolved in distilled water and propylene glycol, sodium citrate, and peppermint oil. ${ }^{12}$

\section{Central Composite Factorial Design}

Preliminary studies suggested that the key factors that influenced the evaporation period and drug content were variables such as propylene glycol concentration and sodium citrate concentration in total transdermal spray. Therefore, the effect of these two important formulation variables on evaporation time ( $\mathrm{min}$ ) and drug content of the prepared transdermal spray was systemically investigated using a central composite designresponse surface methodology (CCD-RSM). Based on the results of preliminary experiments and the feasibility of preparing the transdermal spray at extreme values, the experimental range was selected for each factor. Concentration of propylene glycol (X1) of (5-25 ml) and sodium citrate $(\mathrm{X} 2)$ of $(0.5-2.0 \mathrm{ml})$ was the value range of the variables. There were a total of 13 experiments performed. All of the formulations were prepared in duplicate in these experiments..$^{12,13}$

\section{Characterization}

\section{Pump Delivery $(\mathrm{mg}) /$ Shot Weight}

10 valves were placed in a suitable container which was filled with the test solution. The actuator was ( 0.02 inch orifice) attached to values. One unit was weighted after firing one shot into air, again reweights the unit. This procedure was repeated for 10 times. Average weight of delivered one shot was determined. It should not be more than $10 \%$ of a single weight differs from the average. \% deviation should be less than $6 \%$ above this pump falls. ${ }^{14,15}$

$$
\text { Pump delivery/actuation }(\mu \mathrm{l})=\frac{\text { Individual weight in }(\mathrm{mg})}{\text { Specific gravity of test solution }}
$$

\section{Evaporation Time}

For drying of non-pressurized spray, necessary time was required for the spray film to dry and was recorded. The dry time of getting totally dry film was predictable by spreading the formulation on ethanol delicate paper and totally drying time of spray film was noted. ${ }^{16,17}$

\section{Weight Checking}

It was completed by periodically filling the spray containers with filling lines and then the spray of the bottle moved to a beaker and weighed. ${ }^{18}$

\section{Total No. of Delivery}

A spray bottle was sprayed into the beaker. Lidocaine was extracted using spray with the help of distilled water. The dilution was made with this spray with distilled water to $10 \mathrm{ml} .1 \mathrm{ml}$ aliquot was taken and further diluted to $10 \mathrm{ml}$ and concentration of lidocaine content was evaluated by UV-Visible Spectrophotometer. ${ }^{19}$

\section{Uniformity of Delivered Dose}

The container was thoroughly shaken for 10 s and the discharge was sprayed first with waste. The container for not less than $5 \mathrm{~s}$, agitated for 10 s and spray again to discard. This process was repeated for additional for 3 more actuations. Assemble the contents of the gathering vessel via sequential washes. Determine the content was of the active substance in the communal rinses. Content uniformity was calculated for $6^{\text {th }}, 35^{\text {th }}$, $96^{\text {th }}, 156^{\text {th }}, 210^{\text {th }}, 291^{\text {th }}, 356^{\text {th }}, 412^{\text {th }}$, and $486^{\text {th }}$ shots. ${ }^{20}$

\section{In vitro Skin Permeation Study}

The synthetic membrane of cellulose ester of thickness $0.13 \mathrm{~mm}$ was rinsed with distilled water and soaked into the phosphate buffer for $5 \mathrm{hr}$. 4 sprays of formulation were actuated on the $1.76 \mathrm{~cm}^{2}$ area of synthetic membrane by using a $200 \mathrm{mcl}$ pump (Donor Media). The Phosphate Buffer (PBS, Ph 7.4) was used as receptor media. $5 \mathrm{ml}$ of sample was withdrawn from the media and equal volume was replaced with fresh media. The sample was analyzed by the help of UV-Visible Spectroscopy. ${ }^{21}$

\section{Release Kinetics}

Drug Release from the matrix with different mechanisms like drug diffusion from non-degraded polymer (diffusion-controlled system), polymer degradation, erosion (erosion-controlled system), and drug diffusion enhanced due to polymer swelling. Various kinds of mathematic models applied to the diffusion study like zero order, first order, Higuchi Model, Korsemeyer Peppas Model, Hixson Crowell Model, and BakerLonsdale Model. 22,23

\section{RESULTS}

The central composite design with the surface response technique provides an alternative technique because a large range of variables at varying levels can be explored with a small number of experiments. Table 1 revealed test results for the variables of evaporation time and drug content for evaporation tested. Optimization was achieved with the desirability feature optimum points with respect to fixed limits under which minimum level evaporation time and maximum level drug content. ${ }^{24}$ The results of the experimental design showed that the formulation was significantly affected by the amount of propylene glycol and sodium citrate. The drug's content was high and the duration of evaporation decreased. As shown in Table 1, the best fit for each of the Y1 (Evaporation Time) and Y2 (Drug Content) responses for the quadratic models was found; the quadratic model had the largest $r^{2}$ compared to the linear model and the two-factor model. In order to explain the effects of the variables, interaction and quadratic terms were chosen.

Before it came to determining the most appropriate formulation, the fitness of the model out of linear, two-factor $(2 \mathrm{~F})$ and quadratic model were evaluate due to the analysis of variance $p$-value, correlation coefficient $r^{2}$, predicted and adjusted $r^{2}$ as the indicators in model summary statistics listing. A statistically significant $P$-value below 0.05 was considered. The sign and meaning of the quantitative effect represent the pattern and magnitude of the impact of the term on the response, respectively. In the regression equation, a positive value shows an effect that favors optimization because of a synergistic effect, whereas a negative value implies an opposite or antagonistic interaction between the factor and the response. In three- dimensional model graphs for optimization of transdermal spray with acceptable and satisfactory physicochemical properties, response surface analyses were also plotted. Figures 1 depicts three-dimensional surface response plots for time of evaporation and drug content respectively. To explain the relationship and quadratic effects of two independent plots, on the responses, response surface plots were used..$^{25,26}$

A variance analysis (ANOVA) was conducted for the purpose of evaluating how the quadratic models influence the response and its quantitative effects.

Two dependent value ranges from evaporation time (2.32-4.87 $\mathrm{min}$ ) and Drug content (91.31-98.76 mg). An analysis of the response surface regression using Design Expert software version-11 generated a mathematical relationship between factors and parameters. The $3 \mathrm{D}$ surface response graphs for the most important statistical variables of the 

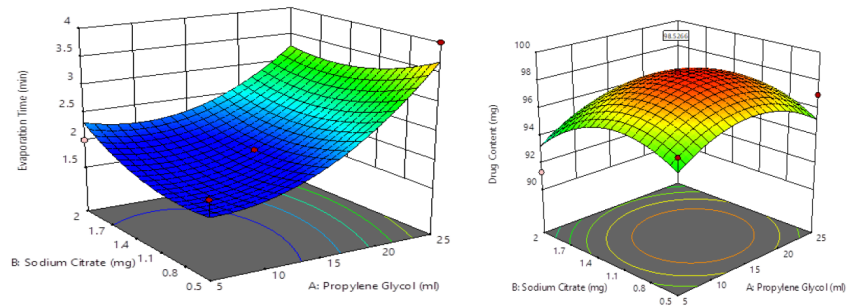

Figure 1: Response surface plot showing the effect of independent variables on Evaporation time and Drug content.

parameters assessed are shown in the Figure 1. The response surface plots showed that higher the concentration of propylene glycol and sodium citrate higher will be the evaporation time and drug content. The different factor combinations resulted in the drug content of lidocaine spray ranging from 91.31 to 98.67 percent for the 13 formulations. The findings obtained in this design suggested that independent factors influencing this design were amount of propylene glycol (X1) and the quadratic term drug/propylene glycol X $2^{2}$ with a $p$ value of $<0.05$. Quantitative estimates of major models show that lipid concentration had the main effect on the drug content for its large positive coefficient (0.568), indicating a higher propylene glycol content of the formulation.

A mathematical model developed for the estimation of drug contents is as follows:

$$
\mathrm{Y}=89.48-0.568 \mathrm{X} 1-8.00 \mathrm{X} 2+0.0310 \mathrm{X} 1 \mathrm{X} 2-0.0190 \mathrm{X} 1^{2} .3 .723 \mathrm{X} 2^{2}
$$

Where $\mathrm{Y}=$ Drug content

$$
\mathrm{X} 1=\text { Propylene glycol (in } \mathrm{ml})
$$

$\mathrm{X} 2=$ Sodium citrate $(\mathrm{in} \mathrm{ml})$

$\mathrm{X} 1 \mathrm{X} 2$ show interaction term, $\mathrm{X} 1^{2}, \mathrm{X} 2^{2}$ are quadratic relationship terms.

The best fitted model for the drug content was quadric fit provided the value of $r^{2}$ (0.9070). For all two responses, Table 2 summarized the effects of the model terms and related $p$ values. A model was considered important at a $95 \%$ confidence level if the $p$ value was $<0.05$. The symbol and value of the quantitative effect represent the tendency and extent of the impact of the word on the response, respectively, respectively. A positive value in the regression equation has an effect that favours optimization because of a synergistic effect, while a negative value implies an opposite or antagonistic interaction between the factor and the answer.

The amount of sodium citrate helps in maintaining the $\mathrm{pH}$ of the spray. It has cosmetic effect on skin after application. The $\mathrm{pH}$ of the formulation was also maintained as the amount of sodium citrate increase but at fixed amount. So at particular amount the $\mathrm{pH}$ of skin cannot be maintained. There was synergetic association of sodium citrate in increasing the drug content. Similarly, the effect of propylene glycol on the evaporation time is clearly showing the regression equation along with response surface plots.

A mathematical model developed for the estimation of Evaporation Time is as follows:

$$
\mathrm{Y}=2.00+0.728 \mathrm{X} 1-0.05182-0.250 \mathrm{X} 1 \mathrm{X} 2+0.5 \mathrm{X}^{2}+0.250 \mathrm{X} 2^{2}
$$

$\mathrm{Y}=$ Evaporation time

$\mathrm{X} 1=$ Propylene glycol

$\mathrm{X} 2=$ Sodium citrate

$\mathrm{X} 1 \mathrm{X} 2$ show interaction term, $\mathrm{X}^{2}$ and $\mathrm{X} 2^{2}$ are quadratic relationship terms.

After evaluating the polynomial equations representing the dependent and independent variables, a further optimization and validation process
Table 2: Comparison of Marketed Formulations and Optimized Batches.

\begin{tabular}{cccc}
\hline $\begin{array}{c}\text { Sr. } \\
\text { No. }\end{array}$ & Parameter Evaluated & $\begin{array}{c}\text { Optimized } \\
\text { Batch }\end{array}$ & $\begin{array}{c}\text { Marketed } \\
\text { Formulation }\end{array}$ \\
\hline 1. & Appearance & Clear solution & Clear solution \\
2. & $\mathrm{pH}$ & 6.8 & 6.6 \\
3. & Assay & $98.31 \%$ & $96.17 \%$ \\
4. & Evaporation rate & $2 \mathrm{~min}$ & $3 \mathrm{~min}$ \\
5. & Average rate per actuation & $0.1964 \mathrm{gm}$ & $0.1956 \mathrm{gm}$ \\
6 & Uniformity of delivered dose & $97.64 \pm 1.934$ & $96.46 \pm 1.934$ \\
7. & Cumulative drug release & $98.88(6 \mathrm{~min})$ & $97.18(9 \mathrm{~min})$ \\
\hline
\end{tabular}

\begin{tabular}{|c|c|c|c|c|c|}
\hline $\begin{array}{l}\dot{0} \\
\text { vi }\end{array}$ &  & 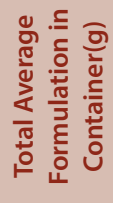 & o & 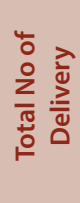 &  \\
\hline 1. & F5 & 96.59 & $98.31 \pm 0.167$ & 487 & $2 \pm 0.2354$ \\
\hline
\end{tabular}

Table 3: Showing the Number of Deliveries of the Container, Evaporation Time and Drug Content.

was carried out with desirable characteristics using the design expert software to test the optimal lidocaine loaded spray formula solution that depended on the prescriptive criteria of maximum drug content and minimum evaporation time. The optimized formulation was F9 was observed with the results of drug content $(98.67 \mathrm{mg}$ ) and evaporation time $(2.81 \mathrm{~min})$ which was quite good agreement with the predicted values.

\section{Shot weight}

The valve was triggered for complete expand and the container was reweighed in grams. Therefore the specific gravity of the test solution was determined to recognize the dose per actuation in $\mathrm{ml}$ at delivery. Specific gravity equivalents the concreteness of the test solution to the concreteness of water. Therefore the densities of individually solution were calculated.10\% not extra than a single weight diverges from the average weight. \% deviancy should be less than $6 \%$. Exceeding this pump fails. The shot weight of F5 was below defined limits.

\section{Assay}

The UV-Spectrophotometer was used for the develop assay. The distilled water was taken as a blank at $\lambda_{\max } 263 \mathrm{~nm}$. Drug content of optimized formulation was calculated; it shows $98.31 \%$ mentioned in Table 3. It complies with the BP standard and indicates that the drug was distributed almost uniformly throughout the formulation and there was no slaughter of drug in the formulation.

\section{Evaporation Time}

It was predictable by spraying the formulation on the skin and the drying time was renowned. Formulation F5 has suitable evaporation time as shown in Table 3.

\section{Weight checking of Container}

Not more than 2 individual masses deviate by more than $25 \%$ value and none of the deviate by more than $35 \%$ from average value then test was complies. The standard deviation of F5 container weight was 0.1492 . 
Table 4: Uniformity of Delivered Dose of Lidocaine Non-Pressurized Topical Spray.

\begin{tabular}{|c|c|c|c|c|c|c|}
\hline \multicolumn{7}{|c|}{ Optimized Formulation F5 } \\
\hline$\sum_{i}^{\circ}$ &  & 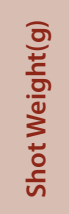 & 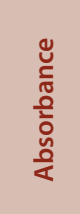 & 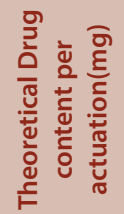 & 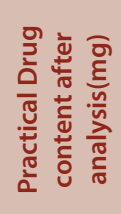 & 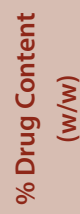 \\
\hline 1 & 6 & 0.20 & 0.253 & 0.210 & 0.204 & 97.14 \\
\hline 2 & 35 & 0.18 & 0.256 & 0.189 & 0.185 & 97.88 \\
\hline 3 & 96 & 0.19 & 0.227 & 0.199 & 0.191 & 95.97 \\
\hline 4 & 156 & 0.20 & 0.261 & 0.210 & 0.206 & 98.09 \\
\hline 5 & 210 & 0.17 & 0.232 & 0.178 & 0.173 & 96.64 \\
\hline 6 & 291 & 0.19 & 0.259 & 0.199 & 0.193 & 96.98 \\
\hline 7 & 356 & 0.20 & 0.254 & 0.210 & 0.209 & 99.52 \\
\hline 8 & 412 & 0.17 & 0.264 & 0.178 & 0.179 & 99.44 \\
\hline 9 & 486 & 0.20 & 0.257 & 0.210 & 0.203 & 97.61 \\
\hline
\end{tabular}

\section{Total Number of Deliveries}

Total amount of delivery of lidocaine non-pressurized topical spray carried out by complete removal of dosage form by one by one actuation into a beaker. Total no. of delivery of F5 formulation is shown in Table 3.

\section{Uniformity of Delivered Dose}

After actuation of pump, the dose of the lidocaine delivered was within the range of $95.97-99.52 \%$. F5 displayed average drug contents per spray of $97.64 \%$, Content uniformity was assessed for 6th, 35th, 96th, 156th, 210th, 291th, 356th, 412th, and 486th. One delivered shot content should not be outside the limits of $75 \%$ to $125 \%$ and no delivered shot content outside the limit of $65 \%$ to $135 \%$ of the average content. If 2 or 3 individuals delivered, shot content was outside the limit of $75 \%$ to $125 \%$, but the individual content was under the limit of $65 \%$ to $135 \%$. Drug content after every actuation was within the limit of $75 \%$ to $125 \%$. Therefore F5, formulation complies with the test, results are shown in Table 4.

\section{Diffusion Study of Optimized Batch (F5) and Marketed Formulation}

The diffusion study finding of the optimized batch shows drug release starting very fast in 1 min cumulative drug release was $61.22 \%$, in $4 \mathrm{~min}$ $86.12 \%$, and in $6 \mathrm{~min}$ almost drug $98.88 \%$ was found to be released from formulation and the diffusion study of marketed formulation was started with $16.15 \%$ in $1 \mathrm{~min}$, in $4 \mathrm{~min} 46.59 \%$, in $9 \mathrm{~min} 97.18 \%$ as shown in Figure 2.

\section{Release Kinetic}

For recognizing the drug release mechanism, the release data of the optimized formulation were inferred by Zero order, First order, Higuchi, Korsmeyer-Peppas model. To recognize the drug release kinetics zeroorder, first order, Higuchi, Peppas plot was created. Value of $\mathrm{r}^{2}$ obtained from different kinetic models were 0.9957, 0.9166, 0.9927 and 0.9864 . Data represented in this experiment, the in vitro release summary that optimized formulations utmost articulated by the zero-order equation as the plots presented high linearity $\left(R^{2} 0.9957\right)$.
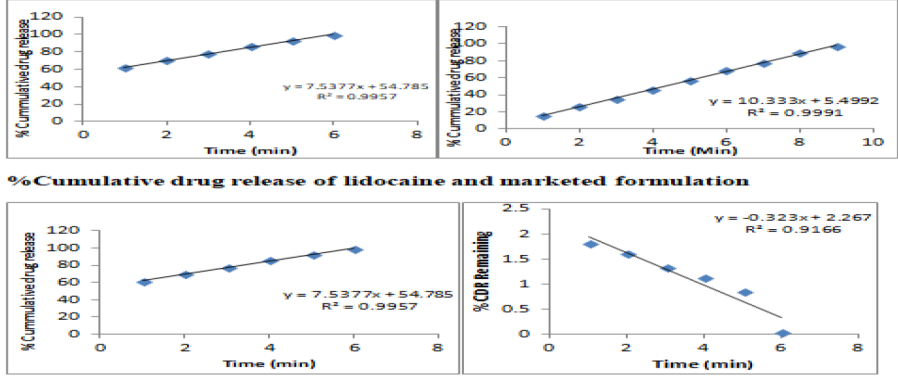

Zero order \& First order release profile of optimized batch (FS)

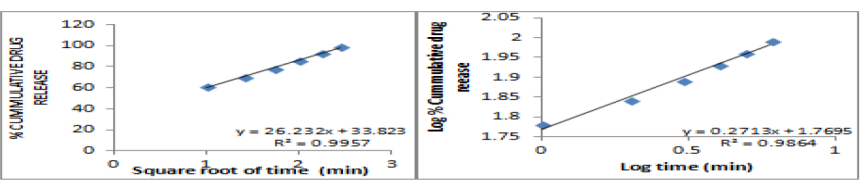

Higuchi \& Korsmeyer Peppad model of optimized batch (Fs)

Figure 2: A: \% Cumulative drug release of Lidocaine and marketed formulation, B: Zero Order and First Order release profile of Optimized Batch (F5), C: Higuchi and Peppas model of Optimized batch (F5).

\section{Results of Marketed Formulation v/s Optimized Batch (F5)}

Lidocaine non-pressurized topical spray compared with marketed lidocaine pressurized topical spray. On the basis of various parameters like appearance, $\mathrm{pH}$, assay, evaporation rate, dose uniformity, average rate per actuation, and cumulative drug release, lidocaine non-pressurized topical spray with marketed spray formulation as shown in Table 2.

\section{DISCUSSION}

Topical non-pressurized drug delivery systems offer lidocaine local anesthesia by nerve blockade at targeted sites on the body. ${ }^{1,2}$ This research explains and added advantage of the novel drug delivery systems like non-pressurized topical sprays using a metered-dose spray dispensing system, which cuts down the cost of the formulation because the propellant is itself costly excipient without therapeutic effect. For storing propellant we need an aluminum container which again adds cost to manufacture, here we were using HDPE bottles for preserving non-pressurized spray and HDPE bottle also stable with spray formulation as indicated by stability studies. ${ }^{3-5,7}$ These topical non-pressurized spray formulations was easy to produce and optimized possessing targeted drug delivery, uniform dosing be possible because of a metereddose container, which further increases patient compliance, more quick anesthetic action, and non-irritancy. Such innovative formulations can be an enhanced upcoming perception in topical dosage form above the conventional dosage forms. ${ }^{8-11}$ The current research study was an effort to develop non-pressurized topical spray which does not comprise any propellant. Lidocaine was identified and characterized by a UV spectrophotometer. Drug- Excipient compatibility study indicated that the drug and various excipients have no interface between them, which represented the physical stability of lidocaine with an excipient. Various trials were carried out using a cooling agent, buffering agent, and preservative, the spray was optimized on the base of composition form stable. The $\mathrm{pH}$ of the formulation optimized to 6.04 to prevent any skin irritation. The central composite design was elected to determine the superlative experimental conditions for formulating the spray formulation. 13 formulations were primed using two factors ( $\mathrm{pH}$ adjuster, i.e, sodium citrate and penetration enhancer, i.e., propylene glycol). The prepared spray formulations were evaluated for diverse parameters such as 
compatibility studies, appearance, drug content, $\mathrm{pH}$, and in vitro release. In the testing of spray container (including pump, actuators, valves, HDPE bottle) the weight checking of the container, the total number of deliveries, uniformity of delivery dose of the container was analyzed and we were found that sprayed the formulation as mentioned within the standard deviation limit of $200 \mathrm{mcl}$ in one actuation it was found that the compositions F5 was perfectly suitable for application by spraying from a pump spray container. Non-pressurized spray system when sprayed on topical sites forms a stable, breathable film, preferably over a fixed surface area. After actuation of pump, the dose of the lidocaine delivered was within the range of 95.97-99.52. Drug release starting very fast in 6 min almost drug $98.88 \%$ was found to be released from formulation. Showing the value of $r^{2}$ obtained from kinetic models for Zero-order, First order, Higuchi model and Korsmeyer Peppas model were 0.9957, $0.9166,0.9927$ and 0.9864 . The diffusion study of marketed formulation was in 9 min $97.18 \%$. The in vitro release utmost articulated by the zeroorder as the plots presented high linearity ( $\left.\mathrm{R}^{2} 0.9957\right)$.

\section{CONCLUSION}

The goal of this study was to create a non-pressurized topical spray that didn't need any propellant. The study was divided into several sections, with the first collecting theoretical and technical data via a broad literature survey, followed by a review of the literature and drug profile, material procurement, and characterization of all materials used in the formulation. A study of drug-excipient compatibility found no interaction between the drug and various excipients, indicating that lidocaine is physically stable with excipient. To determine the best experimental condition for spray formulation, a central composite design was chosen. Two factors were used to prepare 13 formulations ( $\mathrm{pH}$ adjuster i.e sodium citrate and penetration enhancer i.e. It was determined that the spray formulations were compatible with each other and that they had a drug content that was within the acceptable range. The response surface plots showed that higher the concentration of propylene glycol and sodium citrate higher will be the evaporation time and drug content. Tests on a container were conducted to determine the weight of the container and the number of times the formulation was sprayed. The composition F5 was found to be perfectly suitable for spraying from a container within the standard deviation limit of $200 \mathrm{mcl}$. The actuator was $(0.02 \mathrm{inch}$ orifice) attached to values. An unpressurized spray system forms a stable, breathable film when it is sprayed on a topical site. Topical sprays can be activated by pressing a button at the site of application, without contaminating the residual material.

\section{ACKNOWLEDGEMENT}

The authors would like to thank Chaudhary Bansilal University, Bhiwani, Haryana, for providing a research environment.

\section{CONFLICT OF INTEREST}

The authors declare no conflict of interest.

\section{REFERENCES}

1. Bill TJ, Clayman MA, Morgan RF, Gampper TJ. Lidocaine metabolism pathophysiology, drug interactions, and surgical implications. Aesthet Surg J. 2004;24(4):307-11. doi: 10.1016/j.asj.2004.05.001, PMID 19336170.

2. Mudge MC. Review of the analgesic, prokinetic, and anti-inflammatory uses of IV lidocaine. AAEP Proc. 2007;53:245-8.

3. Bhowmik D. Recent advances in novel topical drug delivery system. J Pharm Innov. 2012;1:1(9).
4. Mayba JN, Gooderham MJ. A guide to topical vehicle formulations. J Cutan Med Surg. 2018;22(2):207-12. doi: 10.1177/1203475417743234, PMID 29137492

5. Akomeah FK. Topical dermatological drug delivery: quo vadis? Curr Drug Deliv. 2010;7(4):283-96. doi: 10.2174/156720110793360612, PMID 20695839

6. Prausnitz MR, Langer R. Transdermal drug delivery. Nat Biotechnol. 2008;26(11):1261-8. doi: 10.1038/nbt.1504

7. Rowe RC, Sheskey P, Quinn M. Handbook of pharmaceutical excipients. Libros Digitales-Pharmaceutical Press; 2009.

8. Smolinske SC. CRC handbook of food, drug, and cosmetic excipients. CRC press; 1992

9. Chouthri D, Jawahar N, Mythili L, Radhakrishnan A. Spray technology: A novel approach in transdermal drug delivery. Res J Pharm Technol. 2020;1(13 (2)):1015-27.

10. Umar AK, Butarbutar M, Sriwidodo S, Wathoni N. Film-forming sprays for topical drug delivery. Drug Des Dev Ther. 2020;14:2909-25. doi: 10.2147/DDDT. S256666, PMID 32884234.

11. Parhi $R$, Swain $S$. Transdermal evaporation drug delivery system: concept to commercial products. Adv Pharm Bull. 2018;8(4):535-50. doi: 10.15171/ apb.2018.063, PMID 30607327.

12. Pawar IN, Rajput RR, Vaghani SS, Katara BV. Formulation and evaluation of topical spray containing anti acne agent. Asian J Pharm Technol Innov. 2017;5(24):14-28.

13. Sritharadol R, Nakpheng T, Wan Sia Heng P, Srichana T. Development of a topical mupirocin spray for antibacterial and wound-healing applications. Drug Dev Ind Pharm. 2017;43(10):1715-28. doi: 10.1080/03639045.2017.1339077, PMID 28581830.

14. Mori NM, Patel P, Sheth NR, Rathod LV, Ashara KC. Fabrication and characterization of film-forming voriconazole transdermal spray for the treatment of fungal infection. Bull Fac Pharm Cairo Univ. 2017;55(1):41-51. doi: 10.1016/j. bfopcu.2017.01.001.

15. Chandel A, Goyal AK, Ghosh G, Rath G. Recent advances in aerosolised drug delivery. Biomed Pharmacother. 2019;112(112):108601. doi: 10.1016/j.biopha.2019.108601.

16. LuW, Luo H, WuY, Zhu Z, Wang H. Preparation and characterization of a metered dose transdermal spray for testosterone. Acta Pharm Sin B. 2013;3(6):392-9. doi: 10.1016/j.apsb.2013.10.003

17. Leichtnam ML, Rolland $\mathrm{H}$, Wüthrich $\mathrm{P}$, Guy $\mathrm{RH}$. Formulation and evaluation of a testosterone transdermal spray. J Pharm Sci. 2006;95(8):1693-702. doi: 10.1002/jps.20641, PMID 16795012.

18. Bakshi A, Bajaj A, Malhotra G, Madan M, Amrutiya N. A novel metered dose transdermal spray formulation for oxybutynin. Indian J Pharm Sci. 2008;70(6):733-9. doi: 10.4103/0250-474X.49094, PMID 21369433

19. Sritharadol R, Nakpheng T, Wan Sia Heng P, Srichana T. Development of a topical mupirocin spray for antibacterial and wound-healing applications. Drug Dev Ind Pharm. 2017;43(10):1715-28. doi: 10.1080/03639045.2017.1339077, PMID 28581830.

20. Mori NM, Patel P, Sheth NR, Rathod LV, Ashara KC. Fabrication and characterization of film-forming voriconazole transdermal spray for the treatment of fungal infection. Bull Fac Pharm Cairo Univ. 2017;55(1):41-51. doi: 10.1016/j. bfopcu.2017.01.001.

21. Wani A, Sanghani C, Wani S. Formulation, characterization, and in vitro evaluation of novel microemulsion-based spray for topical delivery of isotretinoin. Asian J Pharm Clin Res. 2018;11(10):226-32. doi: 10.22159/ajpcr.2018.v11i10.27019.

22. Gouda R, Baishya H, Qing Z. Application of mathematical models in drug release kinetics of carbidopa and levodopa ER tablets. J Dev Drugs. 2017;6(02):1-8.

23. Ata S, Rasool A, Islam A, Bibi I, Rizwan M, Azeem MK, Qureshi AUR, lqbal M. Loading of Cefixime to $\mathrm{pH}$ sensitive chitosan based hydrogel and investigation of controlled release kinetics. Int J Biol Macromol. 2020;155:1236-44. doi: 10.1016/j.ijbiomac.2019.11.091. PMID 31730964.

24. Sritharadol R, Nakpheng T, Wan Sia Heng P, Srichana T. Development of a topical mupirocin spray for antibacterial and wound-healing applications. Drug Dev Ind Pharm. 2017;43(10):1715-28. doi: 10.1080/03639045.2017.1339077, PMID 28581830.

25. Aliakbarian B, Sampaio FC, de Faria JT, Pitangui CG, Lovaglio F, Casazza AA, Converti A, Perego P. Optimization of spray drying microencapsulation of olive pomace polyphenols using response surface methodology and artificial neural network. LWT. 2018;93(93):220-8. doi: 10.1016/j.Iwt.2018.03.048.

26. Yingngam B, Kacha W, Rungseevijitprapa W, Sudta $P$, Prasitpuriprecha $C$ and Brantner A. Response surface optimization of spray-dried citronella oil microcapsules with reduced volatility and irritation for cosmetic textile uses. Powder Tech. 2019;1:372-85. 